\title{
A Framework to Analyze Citizen Science Data for Volunteers, Managers, and Scientists
}

\author{
Jason Toft*, Leska Fore ${ }^{\dagger}$, Todd Hass ${ }^{\dagger}$, Barbara Bennett ${ }^{\ddagger}$, Linda Brubaker ${ }^{\ddagger}$, David \\ Brubaker ${ }^{\ddagger}$, Casimir Rice ${ }^{\S}$ and Island County Beach Watchers
}

\begin{abstract}
The continuity of long-term environmental datasets provided by citizen science groups has the potential to address the specific concerns of multiple audiences. We designed an analysis framework based on a 16-year dataset across 40 sites in Puget Sound, WA, USA, which citizen scientists collected by visiting beaches annually and using prescribed protocols to record biodiversity, substrate, and slope. The framework was developed collaboratively by local citizens, agency managers, and academic scientists, incorporating objectives emphasized by each group while addressing overlapping appeal: (1) volunteers highlighted a natural history focus to analyze patterns of biotic and abiotic attributes; (2) managers highlighted a trend analysis to document changes through time; and (3) academic scientists highlighted an impact focus to analyze effects of habitat types and disturbances on biodiversity. By using this framework, we showed that volunteer objectives that describe natural history could categorize beaches according to fauna and flora assemblages and sediment composition. Management objectives that describe trends in eelgrass were stable, with site-specific variability. Science objectives that measure impacts found that dynamic beaches with active sediment movement had higher taxa richness. We conclude that the analysis had broad appeal across users, and we link how natural history, trend, and impact studies can be developed along spatial and temporal components to address multiple objectives and conservation goals.
\end{abstract}

Keywords: Citizen science; biodiversity; intertidal; shoreline; management; conservation

\section{Introduction}

Natural resources monitoring that describes organisms and their linkages to the environment (Tewksbury et al. 2014) can be important for tracking conservation indicators of global biodiversity change (Butchart et al. 2010). Long-term datasets are of high value (Magurran et al. 2010) but can be difficult to generate by scientific institutions because of funding limitations, changes in program direction by agencies, and a focus on requiring new discoveries in grant proposals. Citizen science has successfully been used to fill monitoring gaps, especially when standard field protocols are adopted and carefully implemented (Theobald et al. 2015; Freitag et al. 2016). Recent guidance for citizen science programs (Bonney et al. 2009; Shirk et al. 2012; Pocock et al. 2015) emphasize making data valuable to participants as well as other end-users (e.g., managers, scientists). Here we conduct such an undertaking by providing a framework to analyze

\footnotetext{
* University of Washington, US

+ Puget Sound Partnership, US

₹ Island County Beach Watchers, US

$\S$ National Oceanic and Atmospheric Administration, US

Corresponding author: Jason Toft

(tofty@u.washington.edu)
}

citizen science datasets that incorporates objectives from volunteers, managers, and academic scientists.

Shorelines are vital ecotones with high levels of human use and also places that spark curiosity and a conservation focus for volunteers. Here we focus on a dataset generated in Puget Sound, WA, USA, that used prescribed protocols to sample intertidal beaches at 40 sites covering 16 years (Island County Beach Watchers [ICBW] 2003; Figure 1). Citizen science efforts that are place-based and data-rich, such as this one, have the capacity to collect valid data usable for research on broad temporal and spatial scales, which can be a precursor for conservation action (Bonney et al. 2014; Haywood et al. 2016; Theobald et al. 2015). This capacity is well recognized, and publication of such data in the peer-reviewed literature may best be exemplified by groups focused on birds (Ward et al. 2015; Bishop et al. 2016; McKinley et al. 2017). Invertebrates and marine systems characterized by the ICBW dataset have been understudied by citizen science groups compared to their global proportion (Theobold et al. 2015), and the land - sea interface represented by the intertidal zone is an area of great uncertainty in conservation (Sloan, et al. 2007).

Because of the breadth of the ICBW dataset, our diverse team of state and federal agency staff, academics, and citizen scientists could mine it to address specific policy and citizen science questions and to look for patterns in the underlying ecological processes (Kelling et al. 2009). 

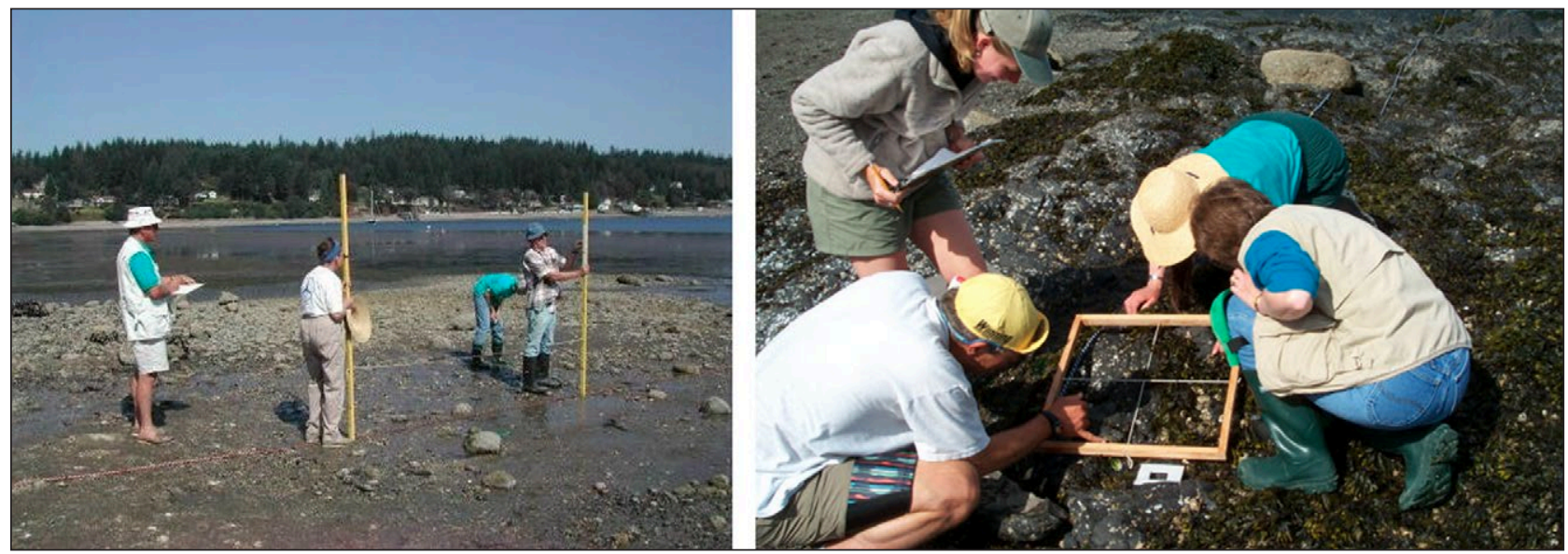

Figure 1: Citizen scientists taking beach measurements along a profile (left) and within a quadrat (right).

Establishing the relationships and dialogue in this collaborative team was essential to make the scientific information available and increase its probability of use (Lauber et al. 2011). The process of our collaboration was initiated In March 2014 at a meeting of the Puget Sound Ecosystem Monitoring Program (PSEMP) Nearshore work group, at which personnel with agency, academic, and citizen scientist expertise met with a goal of connecting volunteer efforts to broader applications. The ICBW dataset was highlighted at this meeting as a prospective source of information that had been consistently entered into a database and maintained, but never analyzed and published. A data analysis team was formed to assess the potential of the dataset to give feedback to the network of volunteers on the utility of the data, fulfill gaps in knowledge for effective management decisions, and address systematic research questions.

During subsequent meetings we developed a framework for addressing the types of studies that a citizen science dataset such as this one could support (Table 1). In particular, the framework allowed us to consider how natural history, trend, and impact studies could be applied to the ICBW dataset that would inform volunteer, management, and science objectives. For example, natural history can be used to describe patterns in nature (Tewksbury et al. 2014), trends can be used to analyze change through time (Ward et al. 2015), and impact studies can be used to measure ecological effects of disturbances (Dethier et al. 2016), all of which have conservation implications. The framework was initially designed to focus on each of our strengths, while recognizing that overlap across our mutual interests would likely emerge as the analysis progressed.

We generated the following questions by linking the quality, quantity, and type of our data to key questions based on our knowledge of the system (Hochachka et al. 2007):

Volunteer (natural history study): What patterns on taxa and beach type emerge from large-scale sampling? We initially heard this question from citizen scientists as they wanted to understand how their data could be used to identify patterns in the biotic and abiotic system, in order to provide feedback to their program relevant to updating educational materials. These observations and descriptions of the natural world also can provide foundations for studying organism-environment linkages (Tewksbury et al. 2014). Using citizen science data to categorize beach types can thus connect observations to broader conservation implications of beach structure and function, providing useful material for education and outreach.

Management (trend study): What trends in eelgrass abundance can we discern from long-term, large-scale datasets? Eelgrass is vital to the health of shoreline systems and is a focus of conservation efforts due to declining populations worldwide (Orth et al. 2006; Waycott et al. 2009). Although the native eelgrass Zostera marina is not faced with extinction in Puget Sound, regional partners have developed an eelgrass recovery strategy (Goehring et al. 2015) that serves as a prototype for other taxa and habitats. Choosing a priority taxon, like eelgrass, linked to a policy goal ensures relevance to managers (Pocock et al. 2015). Furthermore, seagrass monitoring by volunteers can yield high-quality data (Finn et al. 2010), making it a prime target for study by citizen groups.

Science (impact study): Are sites in active sediment areas more diverse ecologically than those with less sediment movement? Sediment dynamics are vital to resilience of beaches, which in Puget Sound are primarily nourished by feeder bluffs that erode and deliver sediment to beaches within drift cells (MacLennan et al. 2013). Shoreline modifications placed at the base of feeder bluffs can impede sediment input, impacting salmon, forage fish, and other nearshore species (Dethier et al. 2016; Munsch et al. 2016). This research question addresses patterns of diversity and impacts of physical processes - both theoretical building blocks of ecology and conservation biology (Connell 1978; Butchart et al. 2010).

We used this framework to design analyses that could apply citizen science data to a broader set of conservation goals. We examined data through three lenses - volunteers, managers, and academic scientists - to envision how data analyses could be appropriately used, then we inspected the appeal of results across our set of user groups throughout the analysis process. This framework 
Table 1: A framework for addressing the types of studies that a citizen science dataset can support, based on volunteer, management, and scientist objectives with application to the Island County Beach Watcher (ICBW) analysis.

\begin{tabular}{lll}
$\begin{array}{l}\text { Objective and } \\
\text { Study Type }\end{array}$ & Description & Examples \\
\hline $\begin{array}{l}\text { Volunteer } \\
\text { Natural History } \\
\text { study type }\end{array}$ & $\begin{array}{l}\text { Characterization } \\
\text { of ecosystem com- } \\
\text { ponents and their } \\
\text { interrelationships }\end{array}$ & $\begin{array}{l}\text { Spatial and temporal } \\
\text { patterns in biotic and } \\
\text { abiotic attributes, and } \\
\text { relationships between } \\
\text { attributes }\end{array}$
\end{tabular}

Management Trend study type

Detection of changes in ecosystem components over time

Science Impact study type

Evaluation of ecological effects of disturbances, especially anthropogenic ones
Long-term changes in the abundance, spatial distribution, and composition of biota, and associated abiotic attributes

\section{Before-After pres-} ence, abundance, and composition of biota and associated abiotic attributes to adverse or beneficial events
Applications

Public education and outreach of natural history. Development of foundational understanding of ecosystems. Establishment of reference or "baseline" conditions.

Meeting management targets.

Surveillance to detect potential natural resource problems regardless of cause.

Assessment of anthropogenic disturbance (e.g., pollutant release, shoreline armoring). Performance of corrective actions (e.g., restoration).

\section{ICBW Analysis}

Intertidal biota taxonomic composition and abundance. Substrate composition. Influences of location and shore types on substrate and intertidal biota.

Inter-annual and spatial patterns in eelgrass cover

Effects of sediment movement and shoreline modifications on diversity of biota includes a broad set of participant and end-user interests, and our goal was to develop a framework that will be valuable for organizing the types of questions that can be answered using ours and others citizen science data (Bonney et al. 2014).

\section{Methods \\ Study area}

Puget Sound is an estuarine fjord, with mixed semidiurnal tides. Sites were opportunistically chosen based on accessibility and interest within the volunteer group, all located on Whidbey and Camano Islands, in Island County. These are large islands that are connected to the mainland via bridges, with a total shoreline length of $338 \mathrm{~km}$. Tidal range is $3-3.5 \mathrm{~m}$. In Island County $35 \%$ of the shoreline is feeder bluff, compared to $18 \%$ Sound-wide (MacLennan et al. 2013). The native eelgrass Zostera marina is the most common seagrass in Puget Sound, estimated at 24,300 ha in 2014 (Christiaen et al. 2016). $Z$. marina is found between $+1.4 \mathrm{~m}$ and $-12 \mathrm{~m}$ mean lower low water (MLLW), optimally between 0 and $-2 \mathrm{~m}$ MLLW.

\section{Data collection}

Beach biodiversity, substrate, and slope data were collected at specific sites following established ICBW procedures that are well documented using standard protocols (ICBW 2003). Training of new volunteers is extensive, with expert training from professionals, hands on training with senior volunteers, and refresher courses each year. Initial training currently costs $\$ 100$ to offset class costs, and is a combination of indoor lectures by experts in the field and guided field trips, for a total of 100 hours. Following training, each trainee is expected to volunteer for a total of 100 hours over the next two years. After collection, data were continually entered into a database and maintained.
Monitoring was completed annually during lowest daytime tides from April-September, with 85\% of sampling occurring May to July. Number of sites sampled each year varied due to capacity of the volunteers. Beach monitoring data included in our analysis consisted of: (1) vertical profile of beach slope and substrate types, and (2) taxa percent cover or counts within quadrats at low-tide elevations (Figure 1). For each beach, a permanent profile line was established by using compass bearings from a reference point above the high tide line to the water. From the starting point, two poles were used to site the horizon and determine beach slope at $10 \mathrm{ft}$ intervals. Substrate type (silt, sand, ground shell debris, gravel, cobble, boulder, erratics) was recorded for presence at each interval. Quadrats were placed on transects parallel to the water's edge at $+1,0$, and -1 ' MLLW tidal elevations. Three $0.25 \mathrm{~m}^{2}$ quadrats were placed $10 \mathrm{ft}$ apart on each transect line (nine total) to measure percent cover or counts of live algae, eelgrass, and invertebrates. Methods were based on those that have a long precedence in the region, with local expertise on identifications of intertidal fauna and flora (Dethier and Schoch 2005). Overall, we analyzed 40 sites for profiles, and 32 for quadrats; quadrat sampling was excluded if the beach was devoid of visible macrobiota (e.g., sandy beaches).

\section{Data analysis}

Data analysis for the volunteer and science objectives (taxa richness and composition) was for 11 years (20022012) of consistent overlapping spatial and temporal components of quadrat and profile/sediment data. The start of this time period corresponded with an effort to solidify methods and expand sites and training (ICBW 2003). Taxa richness was calculated as the number of taxa observed in quadrats for each site averaged across 
all years (5-36 taxa). To be conservative in our analysis and account for any observation bias, we set the level of taxonomic precision at a coarser level than that collected in the field (e.g., barnacle, mussel, green algae, instead of species therein). This step created large morphological groups that are readily identified by citizen scientists and are consistent with groups used in prior studies in Puget Sound (Dethier and Schoch 2005). Analysis for the management objective used eelgrass quadrat data from 16 years (1997-2012) for those 10 sites in which eelgrass occurred (i.e., not all sites had eelgrass, or only had eelgrass 1-2 years of sampling).

Analyses for the volunteer objective used multivariate tests to separate percent cover assemblage data into significant groupings, with subsequent tests on sediment sizes (Supplementary Materials). For the management objective, at each sampling event we averaged the percent cover of $Z$. marina in the nine quadrats. Trends of eelgrass change were graphed using simple linear regression. For the science objective, we assigned site locations to four standardized classifications of shore types that have recently been mapped sound-wide (MacLennan et al. 2013): feeder bluff exceptional, feeder bluff, accretion shoreform, and modified. Feeder bluffs have active erosion of sediments to the nearshore, with evidence of landslides and toe erosion. Those that are "exceptional" deliver greater quantities of sediment to the nearshore more frequently than typical feeder bluffs. Accretion shoreforms are beaches with gradual addition of sediments due to deposition. Modified beaches have some type of artificial shoreline armoring. We used ANOVA with Tukey post-hoc tests to analyze taxa richness and shore types. Taxa richness was also tested for correlations with beach slope variability (Supplementary Materials).

\section{Results}

\section{Volunteer objective}

Based on quadrat measurements, sites significantly clustered into six groups of the lower intertidal assemblage (Figure 2a and Supplementary Materials). The main taxa correlated with the groupings were algae (brown, green, red), eelgrass, and barnacles and mussels. These groupings allowed us to assign a main taxa descriptor of the biological community to each site (Figures 2a, 3). Group A (red algae, low cover) was the only group that was not a dominant descriptor of any of the sites. Group B had the largest contribution of eelgrass, and described seven sites. Groups C and F both consisted mainly of green algae and barnacles, but in different amounts (low and high percent covers, describing four and seven sites, respectively). Group D had the largest contribution of barnacles and mussels, and described two sites. Group E had the largest overall percent cover, described two sites, and was characterized by an algae mix and the largest contribution of brown algae.

Site descriptors included some spatial and temporal patterns (Figure 3). Sites on the west side of Whidbey Island were in Groups E and F (algae mix, green algae, and barnacles high cover, respectively), and sites in Group D (barnacles and mussels) were in Holmes Harbor on the east side of Whidbey Island. Analysis included each year of sampling, and although every site could be assigned a dominant group, there was temporal variation of sites signifying that beaches can be in dynamic states. Group A (red algae, low cover) was a rare case (five occurrences across sites and years) that may signify disturbance or some other transition. Ten of the 32 sites were consistent and had only one main descriptor throughout all years of sampling; these were in groups B (eelgrass) and F (green algae and barnacles, high cover). Fourteen of the sites had rare occurrences in one other grouping, and eight had rare occurrences across multiple groups.

We also assigned sediment characteristics to each significant biological grouping based on average frequency of occurrence of sediment types at MLLW (Figure 2b). All groups showed sediment sizes that generally characterize mixed types of Puget Sound beaches (clay/silt, sand, ground shell debris, gravel, cobbles, and boulders); three groups also had larger erratics (Figure 2b). A multivariate PERMANOVA test on sediment sizes showed a significant result with the six biological groupings $(p=0.0001)$.

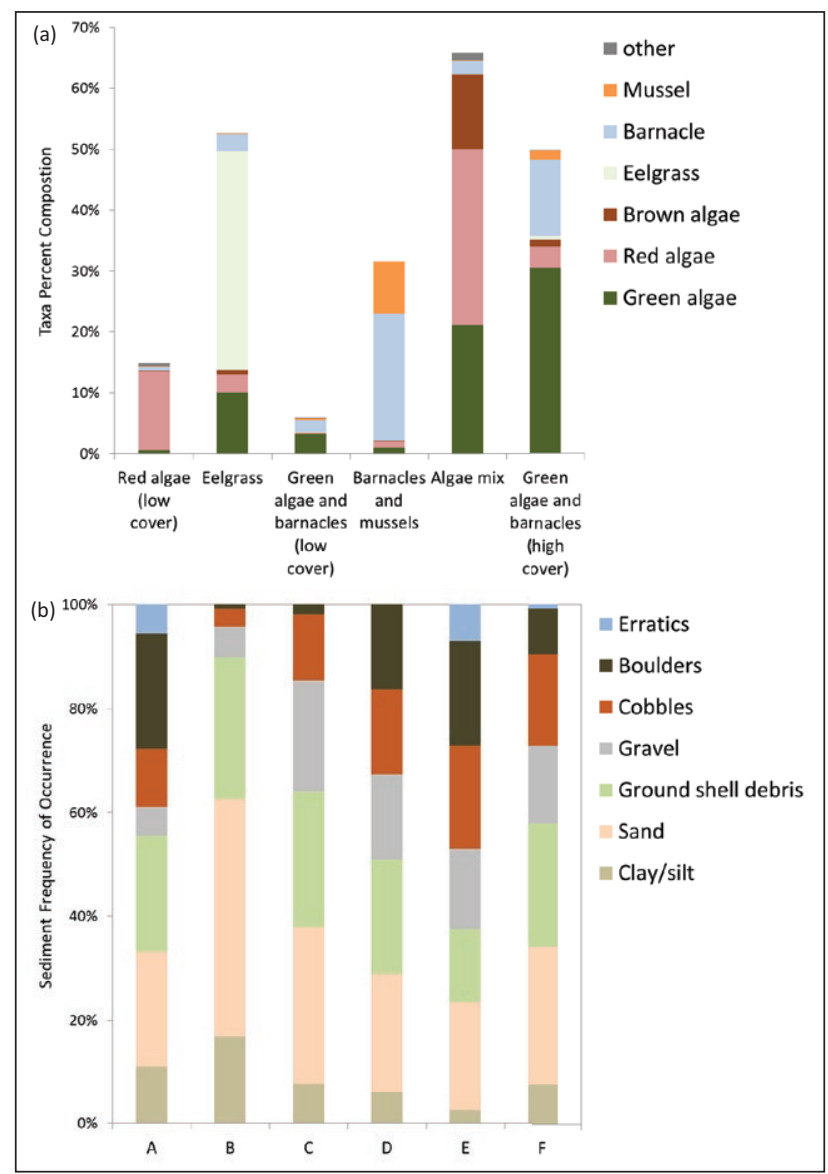

Figure 2: Results of the Volunteer Objective: (a) The six significant groupings of taxa percent composition from quadrat measurements as determined by multivariate cluster analysis, (b) with frequency of occurrence of sediment sizes. 
Pairwise comparisons showed that Group B (eelgrass) had significantly finer sediment sizes than all other groups. Group C (green algae and barnacles, low cover), with mixed sediment sizes, was also unique. Between $\mathrm{D}, \mathrm{E}$, and $\mathrm{F}$ groups, $\mathrm{E}$ and $\mathrm{F}$ were significantly different, partially due to larger contribution of erratics at Group E, which also was the only group with substantial brown algae coverage (Figure 2a).

\section{Management objective}

Analysis of the management objective showed that of the ten sites that had eelgrass present in quadrat measurements over time, five showed no change $\left(\mathrm{R}^{2}<0.04\right.$ and/or average percent composition $<4 \%$ ), four had decreasing percent cover $\left(\mathrm{R}^{2}\right.$ range 0.17 to 0.72 , average percent composition $>20 \%$ ), and one had slightly increasing percent cover $\left(\mathrm{R}^{2}=0.05\right.$, average percent composition 67\%) (Figure 3 and Supplementary Materials). The average slope over time across all sites showed no overall trend $(-0.012)$.

\section{Science objective}

Analysis of the science objective showed that taxa richness in quadrats differed significantly across sites depending on shore type (Figure 4; one-way ANOVA, p < 0.001). Tukey post-hoc tests indicated that both categories of feeder bluffs had significantly higher taxa richness than

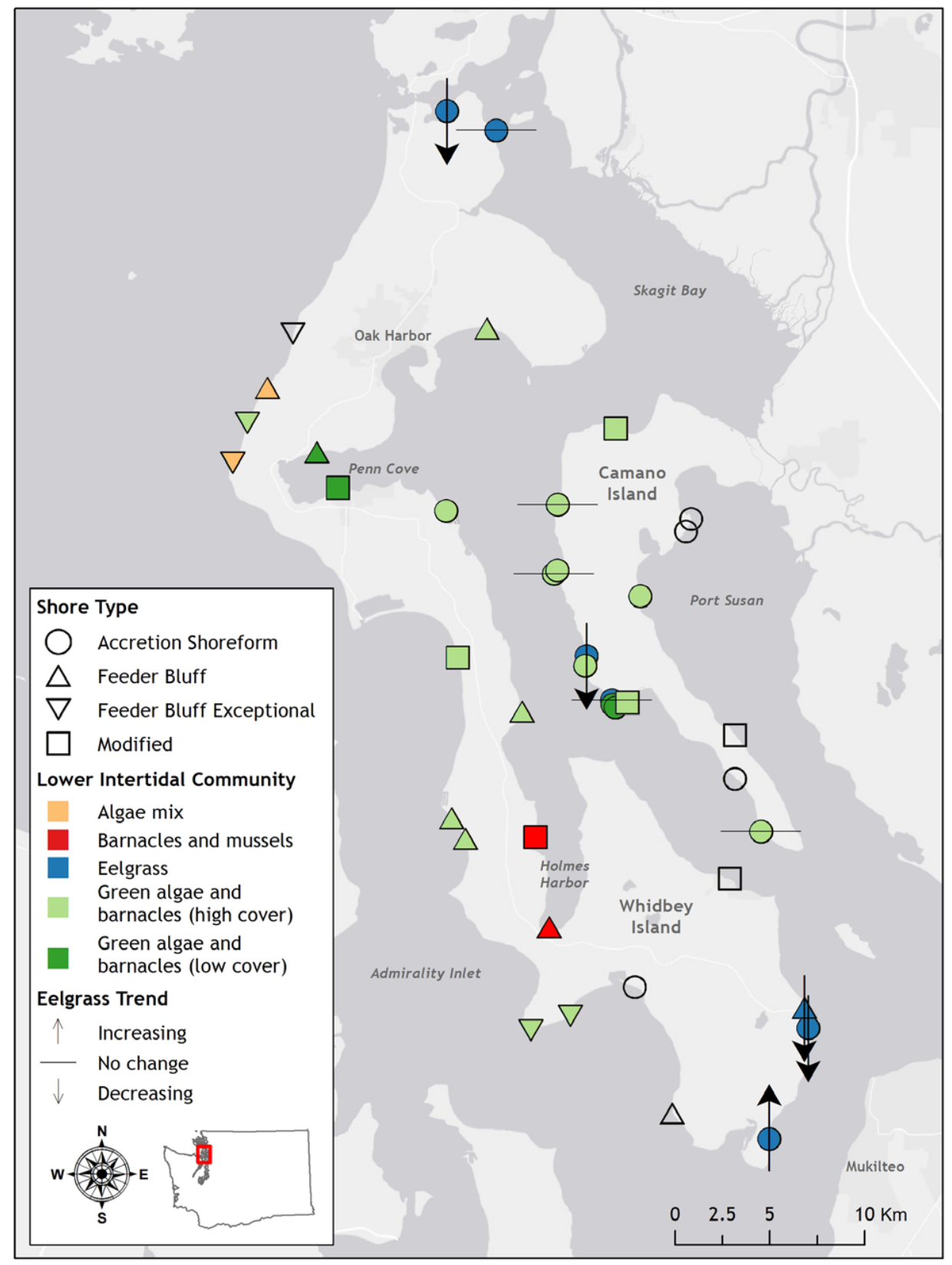

Figure 3: Map of the study sites across Whidbey and Camano Islands. Shown are the shore type categories used in the science objective, results of the volunteer objective for significant groupings in the lower intertidal community, and results of the management objective showing trends in eelgrass. Shapes that are not colored were not sampled for the lower intertidal community. 


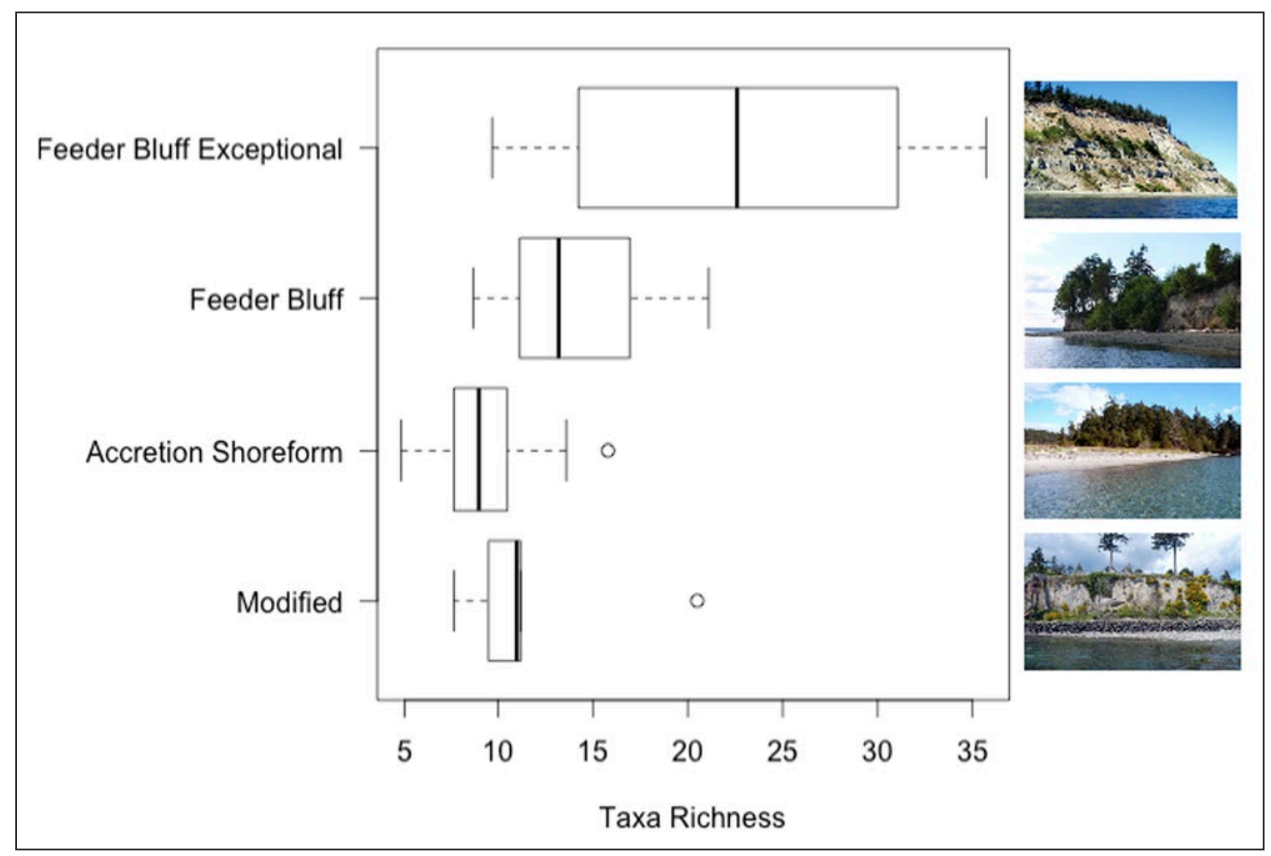

Figure 4: Results of the Science Objective: Boxplots of taxa richness in quadrats for each shore type. The photos represent the four different shore types mapped in MacLennan et al. (2013).

accretional shoreforms, and exceptional feeder bluffs had marginally higher values than modified $(\mathrm{p}<0.1)$. Average taxa richness was also significantly correlated with beach slope variability as measured by the coefficient of variation, with more taxa found on more dynamic beaches (Pearson's correlation $r=0.43, p<0.01$; Supplementary Materials). Overall the assortment of potential taxa was similar; there were no unique taxa at more dynamic beaches.

\section{Discussion}

By combining three types of objectives - volunteer, management, and science - we were able to analyze our dataset to meet multiple needs. Although we started by identifying natural history, trend, and impact studies geared toward specific objectives, we found there to be substantial overlap across interests. This indicates that citizen scientists should be included not only as participants in data collection but also as end users, supporting the idea that a diversity of stakeholders should be included at all stages of program development to maximize data utility (Pocock et al. 2015). We discuss the application of our results for each objective, and highlight insights that can be used by others to promote integrative analyses geared toward conservation goals.

\section{Volunteer objective}

The citizen scientists laid the foundation for describing patterns of intertidal beaches by teaching natural history in training courses and collecting data on beach surface biota and sediments. This effort is notable because knowledge of natural history has been in decline in conservation biology (Tewksbury et al. 2014). Although this data collection can be labeled as descriptive until there is an analytical framework, with the utilization of established proto- cols (ICBW 2003) it lent itself to a thorough analysis at a level beyond the capacity of most citizen science groups. This allowed us to identify significant groupings in patterns of the biological and physical community. Critical to success is that volunteers have substantial training and oversight using consistent field protocols, including data entry and QA/QC. These steps enabled experts outside of the program to focus on analysis and interpretation, forming a beneficial collaboration (Bonney et al. 2009).

This analysis had broad appeal across our interest groups. It informed volunteers about their entire array of beaches, not only those visited by each individual. It informed managers about effective categorization of beach types (Dethier 1990), highlighting the dynamic nature of what can be defined as a "type" because there was some variation over time. Groups B (eelgrass) and $F$ (green algae and barnacles, high cover) were two that were stable through time. Causal effects of temporal variation in other groupings deserve further study - are these assemblages naturally more variable, or are there specific stressors leading to change? Group A, consisting of red algae, appeared to be a particularly transitional state and would be interesting to investigate further.

Scientists can apply these beach descriptions when developing experimental designs that incorporate background information and identify habitat types. Furthermore, results can suggest additional studies to investigate influences on biotic communities. Many variables, including sediment type, govern what lives on a beach. Other variables (e.g., salinity, temperature, wave action) often work at different scales (Dethier and Schoch 2005). The main patterns in sediment sizes are consistent with habitat requirements of taxa; eelgrass requires fine sediments for rooting and rhizome expansion, and barnacles, muscles, and the brown alga kelp and rockweed have 
specialized attachments for rock surfaces. Overlap in sediment sizes for some groups (e.g., D and F) indicates the need for additional sampling to determine multiple scales of physical forces acting on biota. All of these uses of the beach descriptions show how one objective can address multiple interest groups.

\section{Management objective}

Trends in eelgrass can be detected in citizen science data, in our case showing overall stability in percent cover over time. However, the pronounced declines observed at specific sites highlight the need for investigations of stressors that may be causing localized decreases. Our percent cover analysis agrees with other studies in Puget Sound. Analysis of 40 years of presence/absence data have shown stability across the region, with local site scale being the appropriate level for evaluating change (Shelton et al. 2016). The downward trend in Z. marina at specific sites is also consistent with comparable area assessments by the Washington State Department of Natural Resources, which shows 25 declining and 17 increasing sites (Christiaen et al. 2016). These different monitoring efforts highlight the various methods that can be used to evaluate change, which mostly are in agreement on overall stable eelgrass trends.

Although the Puget Sound Partnership established the goal of a $20 \%$ increase in eelgrass area by 2020 (PSP 2014), trend analyses are not showing much change, which brings into question whether a $20 \%$ gain is technically achievable (e.g., through large-scale tidal marsh restoration; Goehring et al. 2015) or is aspirational. Human impacts may be a key stressor at ICBW sites, as those with decreasing eelgrass are at State Parks with recreational use (e.g., low tide beach walks, boats and associated scouring by propellors and anchors), or near ferry terminals. Volunteers have established no-anchor zones at some vulnerable eelgrass beds in Puget Sound, and this community involvement has been successful in deterring unintended impacts. The one ICBW site with high amounts of eelgrass that showed a slight increase is along a residential beach with relatively low levels of public use.

Eelgrass beds are an important habitat worldwide, providing food and shelter for juvenile fishes, crabs, invertebrates, and birds, as well as fixing carbon, mitigating wave energy, and stabilizing shorelines (Orth et al. 2006). For these reasons, datasets that document eelgrass trends will remain vital for measuring conservation effectiveness for years to come (Waycott et al. 2009), and for shaping education and outreach efforts. Again, we found this objective to have broad appeal across our interest groups.

\section{Science objective}

Taxa richness of intertidal biota was higher at dynamic beaches with active sediment movement from feeder bluffs. This is consistent with the intermediate disturbance hypothesis (Connell 1978), in which a non-equilibrium state promotes higher diversity than stable or highly disturbed conditions. In the New Zealand intertidal, highest species richness similarly depends on within-site heterogeneity, temporal variability, and variable wave climate (de Juan and Hewitt 2014). Artificial shoreline armoring is constructed to halt erosion and can impede delivery of sediment to beaches. Our analysis found a weak effect of modified shore types on taxa richness, in concurrence with stronger effects from studies that had a more structured a priori experimental design (Dethier et al. 2016). Spatial trends in our analysis are based on sampled beaches, which are not inclusive of all beach types. For example, all feeder bluffs that were consistently sampled with quadrats were located on Whidbey Island, even though feeder bluffs occur on Camano Island.

As these analyses show, citizen science data are particularly suitable for studying effects of habitat loss and fragmentation on biodiversity (Dickinson et al. 2010), especially as applied to conservation indicators of global declines in biodiversity (Butchart et al. 2010). This has direct links to management, even though the foundation was on a science objective. Sediment nourishment is often a part of beach restoration (Peterson and Bishop 2005), which can include seawall removal (Toft et al. 2014). Due to erosion of feeder bluffs, Puget Sound shorelines may be naturally adapted to sediment nourishment whether natural or artificial, at least for ecological communities associated with high amounts of sediment movement. Conservation of feeder bluff beaches were prioritized as part of the Puget Sound Partnership's target for shoreline armoring removal adopted in 2011, in agreement with science-based recommendations for policy implementation (Dethier et al. 2017). Beyond providing crucial small sediments to the nearshore (which typify the "eelgrass" sediment characteristics in Group B; Figure 2), our findings suggest that this dynamic shoreline category supports higher taxa richness than accretional and modified shorelines. This in turn supports higher trophic levels in the marine food web, such as juvenile fishes that depend on the nursery value of shallow water habitats (Munsch et al. 2016).

Barnard et al. (2017) have highlighted the "early warning" potential for citizen science efforts to detect declines in species of concern and biodiversity. Our findings may be the first biological signal to affirm the decisions of policymakers to prioritize the conservation of feeder bluffs, and classify them as a "saltwater habitat of special concern" (Washington Administrative Code 220-660-320). To what extent such policies are advanced depends on further public engagement and input (McKinley et al. 2017). Community outreach can help encourage landowners to remove rather than maintain armoring at the base of feeder bluffs, especially in cases where safety of people and property will not be affected. In the context of our overall study goals, we found that impact studies, as with natural history and trend studies, can inform science, management, and volunteer objectives, providing a common thread across all three categories of our analysis.

\section{Citizen science implications}

With the benefit of hindsight and results of our analysis, we can conceptualize how a natural history study can be replicated along spatial and temporal components to produce trend and impact studies, which address 
volunteer, management, and science objectives and conservation program goals (Figure 5). We expect that such a conceptual framework will be applicable to others faced with similar analyses across a broad array of geographic areas and biomes, and can recommend the following insights. By replicating through time with a consistent structured data collection using established protocols and ongoing data entry and $\mathrm{QA} / \mathrm{QC}$, a citizen science project can incorporate a temporal component and build from a natural history education and outreach tool to the analysis of trends. In our case, sufficient time had passed that a new analysis team had to be assembled which was different from the original advisor team (Bonney et al. 2009). The amount of work required to analyze and interpret large datasets is not trivial, and our analysis would have been expedited had there been ongoing assessments or dedicated funding. Assessing trends every three years would allow for adaptive actions that can adjust procedures and measure progress toward original goals. By replicating across sites with an explicitly developed experimental design, a citizen science project can incorporate a spatial component and build from a natural history education and outreach tool to the analysis of impacts that evaluate ecological effects of disturbances (Figure 5). The question being asked and the foundation of the experimental design will dictate to what extent both spatial and temporal components are incorporated into the study. Whatever the outcome, the analysis, interpretation, and outreach should involve both participants and end users of the data so that multiple applications of volunteers, management, and scientists can be developed and addressed, which in turn will provide feedback to the original conservation program goals (Figure 5).

It is beneficial to have a plan that can be adaptive to changing needs and status of a citizen science program (Jordan et al. 2016), which may depend on whether the program has short-term or long-term goals. For ICBW, 560 people have trained to be volunteers since the program began, logging 297,943 hours, an average of 532 hours per volunteer. Citizen science programs also can be limited by funding or workload capacity, similar to that at professional institutions, which can hamper longevity of longterm monitoring. Programs should be managed so that the original intent is represented, but also adapted without compromising the quality of long-term datasets. This has recently occurred, as the ICBW program disbanded in 2015 and reformed as the Sound Water Stewards of Island County, which will continue working with the original ICBW mission. The volunteers care about their beaches, and have a strong curiosity and conservation focus that has continuously been fostered over the years. By being proactive in also maintaining a core of science and manager collaborators, citizen science programs can continue to grow and assess their goals and expectations.

With appropriate protocols, training, and oversight, volunteers can produce similar results as scientists for the status of species and natural resources (Danielsen et al. 2014). Although precision of data collected by volunteers is often less than that collected by scientists (e.g., taxonomic resolution and laboratory analyses; Cox et al. 2012), the bulk of data can outweigh other limitations and yield strong patterns (Bonney et al. 2009), leading to recommendations for more focused studies. We found this to

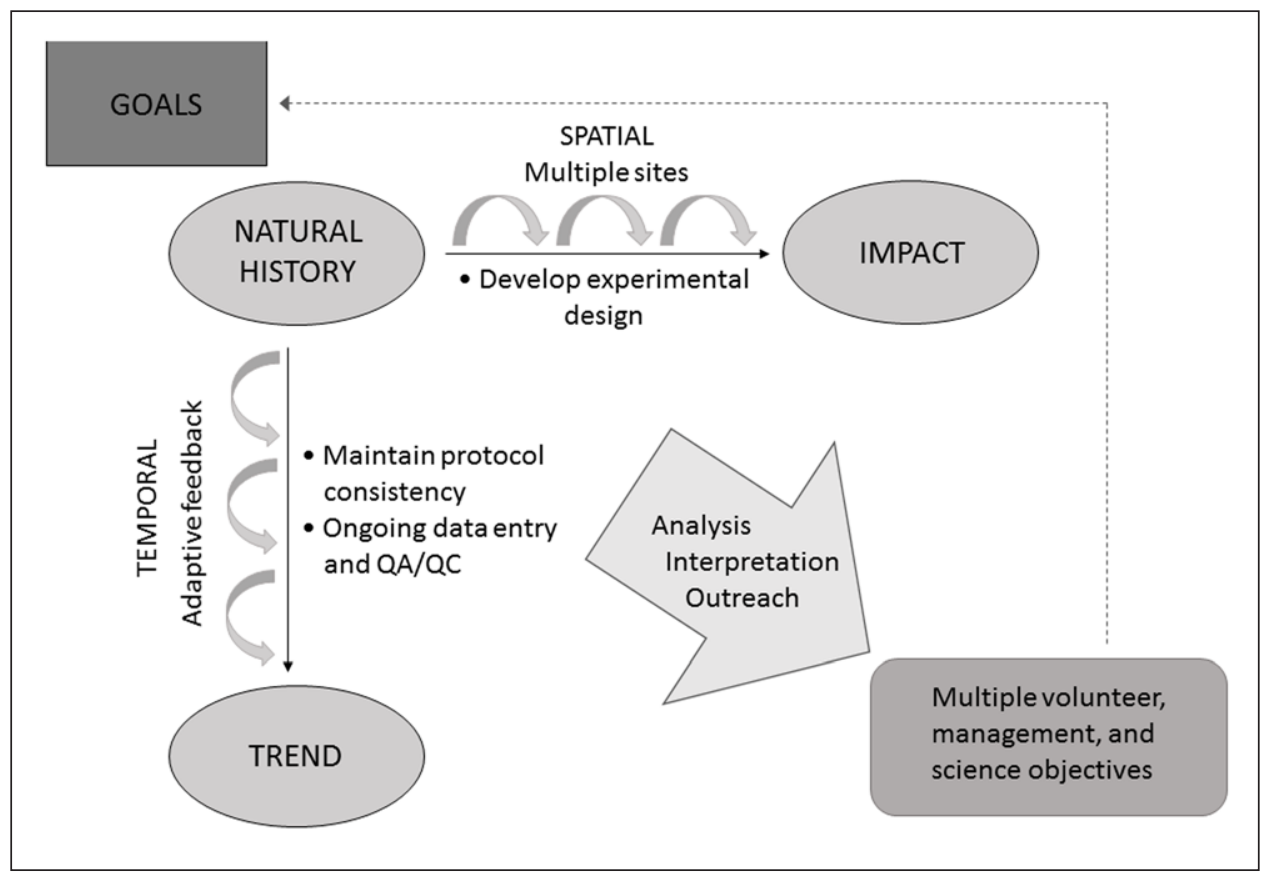

Figure 5: A conceptual diagram linking volunteer, management, and science objectives by illustrating how a natural history study can be replicated along spatial and temporal components to produce trend and impact studies and address conservation program goals. Bulleted statements list main items necessary for incorporating spatial and temporal components. 
be the case in our study, as protocol training was rigorous, technical oversight was provided in the field, and for analysis we conservatively set the level of taxonomic precision to be coarser than that collected in the field, still leading to strong patterns in the bulk of spatial and temporal data. Our recommendations for more focused studies are to: (1) sample biota at higher intertidal elevations where effects of shoreline armoring and restoration are more directly linked (Toft et al. 2014; Dethier et al. 2016); (2) incorporate sediment measurements of percent cover to build upon the biota already surveyed in quadrats; and (3) target specific habitat types such as eelgrass versus non-eelgrass.

Citizen scientists are often not included as co-authors in peer-reviewed manuscripts (Theobald et al. 2015), although surveys show that simple awareness of citizen science projects is one of the main hurdles to overcome, along with the perception of low-quality data (Burgess et al. 2017). Baseline data can be useful for many conservation topics including some that can be continuously addressed, such as trends in seabirds (Ward et al. 2015, Bishop et al. 2016) or eelgrass in our analysis, and some that are difficult to foresee in advance such as trophic cascades caused by the sea star wasting disease (Schultz et al. 2016). When citizen science data collection is geared toward addressing management questions, sufficient planning and oversight are required to ensure that the data are timely and applicable to conservation needs (McKinley et al. 2017). The programmatic framework that is necessary to build large datasets can be difficult to maintain, and again, requires adaptive components through time. For citizen-scientist collected data, we found that volunteer engagement is as important as science and management at the analysis level. The collaborative effort helped to frame the analysis so that it would be useful to multiple groups and would increase the availability and use of scientific information in collaborative conservation (Lauber et al. 2011). It is clear that citizen science data can hold a wealth of information, and will be invaluable for addressing future conservation scenarios.

\section{Additional File}

The additional file for this article can be found as follows:

\section{- Supplementary Materials. Additional Methods on Data Analysis. DOI: https://doi.org/10.5334/ cstp.100.s1}

\section{Acknowledgements}

We thank all of the many volunteers who participated in years of data collection, particularly Don Meehan, Jan Holmes, and Mary Jo Adams who were instrumental in launching and sustaining this work. The Puget Sound Ecosystem Monitoring Program (PSEMP) Nearshore work group, supported by the Puget Sound Partnership and Washington Sea Grant, was the incubator for this research. Thank you to Jen Burke and Mary Ramirez for GIS and mapping expertise. Jodie Toft commented on a previous version of this manuscript. We dedicate this publication to Casey (Casimir) Rice, whose enthusiasm for science and the nearshore of the Pacific Northwest brought us all together.

\section{Competing Interests}

The authors have no competing interests to declare.

\section{References}

Barnard, P., Altwegg, R., Ebrahim, I. and Underhill, L.G., 2017. Early warning systems for biodiversity in southern Africa - how much can citizen science mitigate imperfect data? Biological Conservation 208: 183-188. DOI: https://doi.org/10.1016/j.biocon.2016.09.011

Bishop, E., Rosling, G., Kind, P. and Wood, F., 2016. Pigeon Guillemots on Whidbey Island, Washington: A six-year monitoring study. Northwestern Naturalist 97: 237245. DOI: https://doi.org/10.1898/NWN15-31.1

Bonney, R., Cooper, C.B., Dickinson, J., Kelling, S., Phillips, T., Rosenberg, K.V. and Shirk, J., 2009. Citizen science: a developing tool for expanding science knowledge and scientific literacy. BioScience 59(11): 977-984. DOI: https://doi.org/10.1525/bio.2009.59.11.9

Bonney, R., Shirk, J.L., Phillips, T.B., Wiggins, A., Ballard, H.L., Miller-Rushing, A.J. and Parrish, J.K., 2014. Next steps for citizen science. Science 343(6178): 14361437. DOI: https://doi.org/10.1126/science.1251554

Burgess, H.K., DeBey, L.B., Froehlich, H.E., Schmidt, N., Theobald, E.J., Ettinger, A.K., HilleRisLambers, J., Tewksbury, J. and Parrish, J.K., 2017. The science of citizen science: Exploring barriers to use as a primary research tool. Biological Conservation 208: 113-120. DOI: https://doi.org/10.1016/j.biocon.2016.05.014

Butchart, S.H.M., Walpole, M., Collen, B., van Strien, A., Scharlemann, J.P.W., Almond, R.E.A., Baillie, J.E.M., Bomhard, B., Brown, C., Bruno, J., Carpenter, K.E., Carr, G.M., Chanson, J., Chenery, A.M., Csirke, J., Davidson, N.C., Dentener, F., Foster, M., Galli, A., Galloway, J.N., Genovesi, P., Gregory, R.D., Hockings, M., Kapos, V., Lamarque, J.-F., Leverington, F., Loh, J., McGeoch, M.A., McRae, L., Minasyan, A., Morcillo, M.H., Oldfield, T.E.E., Pauly, D., Quader, S., Revenga, C., Sauer, J.R., Skolnik, B., Spear, D., Stanwell-Smith, D., Stuart, S.N., Symes, A., Tierney, M., Tyrrell, T.D., Vié, J.C. and Watson, R., 2010. Global biodiversity: Indicators of recent declines. Science 328(5982): 1164-1168. DOI: https://doi.org/10.1126/science.1187512

Christiaen, B., Dowty, P., Ferrier, L., Gaeckle, J., Berry, H., Stowe, J. and Sutton, E., 2016. Puget Sound Submerged Vegetation Monitoring Program 2014 Report. Washington State Department of Natural Resources, Olympia, Washington. Available at: http://file.dnr. wa.gov/publications/aqr_nrsh_svmp_report_2014. pdf (last accessed 15 May 2017).

Connell, J.H., 1978. Diversity in tropical rain forests and coral reefs. Science 199(4335): 1302-1310. DOI: https://doi.org/10.1126/science.199.4335.1302

Cox, T.E., Philippoff, J., Baumgartner, E. and Smith, C.M., 2012. Expert variability provides perspective on the strengths and weaknesses of citizen-driven intertidal monitoring program. Ecological Applications 22(4): 1201-1212. DOI: https://doi.org/10.1890/11-1614.1 
Danielsen, F., Jensen, P.M., Burgess, N.D., Altamirano, R., Alvioloa, P.A., Andrianandrasana, H., Brashares, J.S., Burton, A.C., Coronado, I., Corpuz, N., Enghoff, M., Fjeldså, J., Funder, M., Holt, S., Hübertz, H., Jensen, A.E., Lewis, R., Massao, J., Mendoza, M.M., Ngaga, Y., Pipper, C.B., Poulsen, M.K., Rueda, R.M., Sam, M.K., Skielboe, T., Sørensen, M., and Young, R., 2014. A multicountry assessment of tropical resource monitoring by local communities. BioScience 64(3): 236-251. DOI: https://doi.org/10.1093/biosci/biu001

de Juan, S., and Hewitt, J., 2014. Spatial and temporal variability in species richness in a temperate intertidal community. Ecography 37(2): 183-190. DOI: https:// doi.org/10.1111/j.1600-0587.2013.00048.x

Dethier, M.N., 1990. A Marine and Estuarine Habitat Classification System for Washington State. Washington State Department of Natural Resources. Olympia, Washington. 2014 update available at: https://www. eopugetsound.org/habitats/shore-types (last accessed 15 May 2017).

Dethier, M.N., Raymond, W.W., McBride, A.N., Toft, J.D., Cordell, J.R., Ogston, A.S., Heerhartz, S.M. and Berry, H.D., 2016. Multiscale impacts of armoring on Salish Sea shorelines: Evidence for cumulative and threshold effects. Estuarine, Coastal \& Shelf Science 175: 106117. DOI: https://doi.org/10.1016/j.ecss.2016.03.033

Dethier, M.N. and Schoch, G.C., 2005. The consequences of scale: assessing the distribution of benthic populations in a complex estuarine fjord. Estuarine, Coastal \& Shelf Science 62(1-2): 253-270. DOI: https://doi. org/10.1016/j.ecss.2004.08.021

Dethier, M.N., Toft, J.D. and Shipman, H., 2017. Shoreline armoring in an inland sea: Science-based recommendations for policy implementation. Conservation Letters 10: 626-633. DOI: https://doi.org/10.1111/ conl.12323

Dickinson, J.L., Zuckerberg, B. and Bonter, D.N., 2010. Citizen Science as an ecological research tool: Challenges and benefits. Annual Review of Ecology, Evolution, and Systematics 41: 149-72. DOI: https://doi.org/10.1146/ annurev-ecolsys-102209-144636

Finn, P.G., Udy, N.S., Baltais, S.J., Price, K. and Coles, L., 2010. Assessing the quality of seagrass data collected by community volunteers in Moreton Bay Marine Park, Australia. Environmental Conservation 37(1): 83-89. DOI: https://doi.org/10.1017/S0376892910000251

Freitag, A., Meyer, R. and Whiteman, L., 2016. Strategies Employed by Citizen Science Programs to Increase the Credibility of Their Data. Citizen Science: Theory and Practice 1(1). DOI: https://doi.org/10.5334/cstp.6

Goehring, M., Gaeckle, J., Hass, T. and Brandt, S., 2015. Puget Sound Eelgrass (Zostera marina) Recovery Strategy. Washington State Department of Natural Resources, Olympia, Washington. Available at: http:// file.dnr.wa.gov/publications/aqr_nrsh_eelgrass_strategy_final.pdf (last accessed 15 May 2017).

Haywood, B.K., Parrish, J.K. and Dolliver, J., 2016. Placebased and data-rich citizen science as a precursor for conservation action. Conservation Biology 30(3): 476486. DOI: https://doi.org/10.1111/cobi.12702
Hochachka, W.M., Caruana, R., Fink, D., Munson, A., Riedewald, M., Sorokina, D. and Kelling, S., 2007. Datamining discovery of pattern and process in ecological systems. The Journal of Wildlife Management 71(7): 2427-2437. DOI: https://doi.org/10.2193/2006-503

Island County Beach Watchers (ICBW), 2003. Beach Monitoring Procedures. Island County/Washington State University Beach Watchers, Coupeville, Washington. Available at: http://soundwaterstewards.org/icbw/ monitoring/data/manual03.pdf (last accessed 15 May 2017).

Jordan, R., Gray, S., Sorensen, A., Newman, G., Mellor, D., Newman, G., Hmelo-Silver, C., LaDeau, S., Biehler, D. and Crall, A., 2016. Studying citizen science through adaptive management and learning feedbacks as mechanisms for improving conservation. Conservation Biology 30(3): 487-495. DOI: https://doi.org/10.1111/ cobi.12659

Kelling, S., Hochachka, W.M., Fink, D., Riedewald, M., Caruana, R., Ballard, G. and Hooker, G., 2009. Dataintensive science: A new paradigm for biodiversity studies. BioScience 59(7): 613-620. DOI: https://doi. org/10.1525/bio.2009.59.7.12

Lauber, T.B., Stedman, R.C., Decker, D.J. and Knuth, B.A., 2011. Linking knowledge to action in collaborative conservation. Conservation Biology 25(6): 1186-1194. DOI: https://doi.org/10.1111/j.1523-1739.2011.01742.x

MacLennan, A.J., Johannessen, J.W., Williams, S.A., Gerstel, W.J., Waggoner, J.F. and Bailey, A., 2013. Feeder Bluff Mapping of Puget Sound. Coastal Geologic Services: Bellingham, Washington. Available at: https://fortress.wa.gov/ecy/publications/parts/1406016part 1. pdf (last accessed 15 May 2017).

Magurran, A.E., Baillie, S.R., Buckland, S.T., Dick, J.M., Elston, D.A., Scott, E.M., Smith, R.I., Somerfield, P.J. and Watt, A.D. 2010. Long-term datasets in biodiversity research and monitoring: assessing change in ecological communities through time. Trends in Ecology and Evolution 25(10): 574-582. DOI: https://doi. org/10.1016/j.tree.2010.06.016

McKinley, D.C., Miller-Rushing, A.J., Ballard, H.L., Bonney, R., Brown, H., Cook-Patton, S.C., Evans, D.M., French, R.A., Parrish, J.K., Phillips, T.B., Ryan, S.F., Shanley, L.A., Shirk, J.L., Stepenuck, K.F., Weltzin, J.F., Wiggins, A., Boyle, O.D., Briggs, R.D., Chapin, S.F., III, Hewitt, D.A., Preuss, P.W. and Soukup, M.A., 2017. Citizen science can improve conservation science, natural resource management, and environmental protection. Biological Conservation 208: 15-28. DOI: https://doi. org/10.1016/j.biocon.2016.05.015

Munsch, S.H., Cordell, J.R. and Toft, J.D., 2016. Fine-scale habitat use and behavior of a nearshore fish community: nursery functions, predation avoidance, and spatiotemporal habitat partitioning. Marine Ecology Progress Series 557: 1-15. DOI: https://doi.org/10.3354/ meps 11862

Orth, R.J., Carruthers, T.J.B., Dennison, W.C., Duarte, C.M., Fourqurean, J.W., Heck, K.L., Jr., Hughes, A.R., Kendric, G.A., Kenworthy, W.J., Olyarnik, S., Short, F.T., Waycott, M. and Williams, S.L., 2006. A global crisis for seagrass 
ecosystems. Bioscience 56(12): 987-996. DOI: https:// doi.org/10.1641/0006-3568(2006)56[987:AGCFSE]2 .0.CO;2

Peterson, C.H. and Bishop, M.J., 2005. Assessing the environmental impacts of beach nourishment. Bioscience 55(10): 887-896. DOI: https://doi.org/10.1641/00063568(2005)055[0887:ATEIOB]2.0.CO;2

Pocock, M.J.O., Newson, S.E., Henderson, I.G., Peyton, J., Sutherland, W.J., Noble, D.G., Ball, S.G., Beckmann, B.C., Biggs, J., Brereton, T., Bullock, D.J., Buckland, S.T., Edwards, M., Eaton, M.A., Harvey, M.C., Hill, M.O., Horlock, M., Hubble, D.S., Julian, A.M., Mackey, E.C., Mann, D.J., Marshall, M.J., Medlock, J.M., O’Mahony, E.M., Pacheco, M., Porter, K., Prentice, S., Procter, D.A., Roy, H.E., Southway, S.E., Shortall, C.R., Stewart, A.J.A., Wembridge, D.E., Wright, M.A. and Roy, D.B., 2015. Developing and enhancing biodiversity monitoring programmes: a collaborative assessment of priorities. Journal of Applied Ecology 52(3): 686-695. DOI: https://doi.org/10.1111/1365-2664.12423

Puget Sound Partnership (PSP), 2014. The 2014/2015 Action Agenda for Puget Sound. Available at: http://www.psp.wa.gov/action_agenda_center. php (last accessed 15 May 2017).

Schultz, J.A., Cloutier, R.N. and Côté, I.M., 2016. Evidence for a trophic cascade on rocky reefs following sea star mass mortality in British Columbia. PeerJ 4: e1980 DOI: https://doi.org/10.7717/peerj.1980

Shelton, A.O., Francis, T.B., Feist, B.E., Williams, G.D., Lindquist, A. and Levin, P.S., 2016. Forty years of seagrass population stability and resilience in an urbanizing estuary. Journal of Ecology DOI: https://doi. org/10.1111/1365-2745.12682

Shirk, J.L., Ballard, H.L., Wilderman, C.C., Phillips, T., Wiggins, A., Jordan, R., McCallie, E., Minarchek, M., Lewenstein, B.V., Krasny, M.E. and Bonney, R., 2012. Public participation in scientific research: a framework for deliberate design. Ecology and Society 17(2): 29. DOI: https://doi.org/10.1111/j.1523-1739.2007.00731.x

Sloan, N.A., Vance-Borland, K., and Ray, G.C., 2007. Fallen between the cracks: Conservation linking land and sea. Conservation Biology 21(4): 897-898. DOI: https://doi. org/10.1111/j.1523-1739.2007.00731.x

Tewksbury, J.J., Anderson, J.G., Bakker, J.D., Billo, T.J., Dunwiddie, P.W., Groom, M.J., Hampton, S.E., Herman, S.G., Levey, D.J., Machnicki, N.J., and Del Rio, C.M., 2014. Natural history's place in science and society. BioScience 64(4): 300-310. DOI: https://doi.org/10.1093/ biosci/biu032

Theobald, E.J., Ettinger, A.K., Burgess, H.K., DeBey, L.B., Schmidt, N.R., Froehlich, H.E., Wagner, C., HilleRisLambers, J., Tewksbury, J., Harsch, M.A., and Parrish, J.K., 2015. Global change and local solutions: Tapping the unrealized potential of citizen science for biodiversity research. Biological Conservation 181: 236-244. DOI: https://doi.org/10.1016/j.biocon.2014.10.021

Toft, J.D., Cordell, J.R., and Armbrust, E.A., 2014. Shoreline armoring impacts and beach restoration effectiveness vary with elevation. Northwest Science 88(4): 367-375. DOI: https://doi.org/10.3955/046.088.0410

Ward, E.J., Marshall, K.N., Ross, T., Sedgley, A., Hass, T., Pearson, S.F., Joyce, G., Namel, N.J., Hodum, P.J., and Faucett, R., 2015. Using citizen-science data to identify local hotspots of species occurrence. PeerJ 3: e704. DOI: https://doi.org/10.7717/peerj.704

Waycott, M., Duarte, C.M., Carruthers, T.J.B., Orth, R.J., Dennison, W.C., Olyarnik, S., Calladine, A., Fourqurean, J.W., Heck, K.L., Jr., Hughes, A.R., Kendrick, G.A., Kenworthy, W.J., Short, F.T., and Williams, S.L., 2009. Accelerating loss of seagrasses across the globe threatens coastal ecosystems. Proceedings of the National Academy of Sciences 106(30): 12377-12381. DOI: https://doi.org/10.1073/pnas.0905620106

\footnotetext{
How to cite this article: Toft, J., Fore, L., Hass, T., Bennett, B., Brubaker, L., Brubaker, D., Rice, C. and Island County Beach Watchers. 2017 A Framework to Analyze Citizen Science Data for Volunteers, Managers, and Scientists. Citizen Science: Theory and Practice, 2(1): 9, pp.1-11, DOI: https://doi.org/10.5334/cstp.100
}

Submitted: 08 February 2017 Accepted: 11 October 2017 Published: 28 December 2017

Copyright: ( $) 2017$ The Author(s). This is an open-access article distributed under the terms of the Creative Commons Attribution 4.0 International License (CC-BY 4.0), which permits unrestricted use, distribution, and reproduction in any medium, provided the original author and source are credited. See https://creativecommons.org/licenses/by/4.0/. 